\title{
Preliminary results of the impact of 3D-visualization resources in the area of graphic expression on the motivation of university students
}

\author{
Paula Triviño-Tarradas ${ }^{1}\left[\right.$ - Alejandro Mohedo-Gatón ${ }^{2} \cdot$ Rafael Enrique Hidalgo Fernández ${ }^{1}$. \\ Francisco-Javier Mesas-Carrascosa ${ }^{1}$. Pilar Carranza-Cañadas ${ }^{1}$
}

Received: 8 July 2021 / Accepted: 10 November 2021 / Published online: 27 November 2021

(C) The Author(s) 2021

\begin{abstract}
Augmented reality and virtual reality are innovative technologies applied to the area of graphic expression with increasing influence on the teaching-learning process. Although these innovative resources enable new forms of teaching, it remains unclear how these artificial applications can impact students' motivation. The aim of this paper was to evaluate how virtual exercises increase the motivation level in different typologies of university students. The sample was composed of graduate (master's degree) and undergraduate students (three engineering degrees) of the University of Cordoba. These tools were available to students through four devices: mobile phones, tablets, computers and virtual reality goggles. The motivation of the students was evaluated through the modified Instructional Materials Motivation Survey by the attention, relevance, confidence and satisfaction motivational model. The results obtained through a 5-point Likert scale showed that these innovative resources significantly improved the students' motivation level, especially concerning the 'relevance' aspect $(\mathrm{M}=4.01$; $\mathrm{SD}=0.98)$. The virtual resources also increased the understanding of the exercises and their spatial vision $(\mathrm{M}=3.80$; $\mathrm{SD}=1.14)$. Of the total sample, $63.83 \%$ students considered the virtual reality goggles as the most suitable device to visualize graphic expression exercises.
\end{abstract}

Keywords Virtual reality $\cdot$ Augmented reality $\cdot$ Motivation level $\cdot$ ARCS model $\cdot$ Expression

Paula Triviño-Tarradas

ig2trtap@uco.es

Alejandro Mohedo-Gatón

alejandro.mohedo@juntadeandalucia.es

Rafael Enrique Hidalgo Fernández

rhidalgo@uco.es

Francisco-Javier Mesas-Carrascosa

fjmesas@uco.es

Pilar Carranza-Cañadas

ir1carr@uco.es

1 Department of Graphic Engineering and Geomatics, University of Cordoba, Campus de Rabanales, 14071 Córdoba, Spain

2 Andalusian Public Education Agency, Ministry of Education and Sport. Cordoba Delegation, Córdoba, Spain

\section{Introduction}

Geometry is an important part of the basic education of engineering universities. Learning geometry is not a simple procedure, due to its difficulty and need for abstraction. One of the most relevant abilities in working with geometry is the spatial ability or spatial visualization, which, according to Kahle (1983), is the ability to manipulate an object or a pattern in the imagination. It is known that the visualization skill is an important tool required for engineers to project and design effectively (Hsi et al. 1997; Zgoul and Kilani 2009). The ability to visualize problems is essential for engineering students (Sorby and Baartmans 2000; Baranová and Katrenicová 2018), as it is linked to their future success in their professional work (Adanez and Dias Velasco 2002). In addition to traditional visualization methods linked to engineering design (Lord 1985), nowadays, improved visualization skills are important (Sorby and Baartmans 2000). Therefore, there are other approaches based on the inclusion of Information and Communication Technology (ICT) and 
innovative technologies which influence the teaching-learning process in graphical engineering subjects, such as videogames (Feng et al. 2007), multimedia technologies (Gerson et al. 2001), CAD applications (Chester 2007) and virtual and augmented reality (Chen et al. 2011) among others. Tang and Austin (2009) studied the enhanced level of perception of student-learners caused by the mixed implementation of different teaching technologies. There was a long debate about whether the media influence learning or not (Morrison 1994). After many years of debates, educational technology researchers have concluded that a more appropriate question concerns the strategies that are used with technology and the conditions (Petersen et al. 2020). Nowadays, new technologies applied in the world of education are becoming more popular (Hwang and Arbaugh 2009), particularly in engineering and technical degrees (Viegas et al. 2018), being encouraged by a highly technologized world (Bennett et al. 2008). Considering motivation as a predictor of academic performance (Barton et al. 2021), numerous previous studies conducted with pre-university students in the field of education conclude that the use of technology supports, and even increases, student motivation (Taran 2005; Chang and Hwang 2018). However, few studies have analyzed the impact of the application of AR and VR on the motivation of university students (Pellas et al. 2019). Although Prince and Felder (2006) state that the only motivation that students get, if any, is that the content will be important later in their future careers, authors such as Parras-Burgos et al. (2020) have recently assessed the positive acceptance of the use of these artificial technologies in the engineering field for graphic expression subjects. Thus, although the learning process is a complex process that cannot be understood only as the relationship between students' response to technology and motivation, previous studies show that certain technologies improve middle-school students' motivation (Di Serio et al. 2013) and help them become better students (Tang and Austin 2009). In engineering education, practical lectures play a crucial role, as they allow learners to feel their interaction with the real phenomena (Millar 2004). Succeeding in such abstract engineering disciplines requires students to be previously motivated, trained and qualified in these subject matters, as well as to have a good spatial vision (Sorby 2009). Spatial ability has been found to be related to problem representation and plays a crucial role in engineering education and is not limited to image visualization, as it extends to thinking during problem solving, requiring mental representation (Duffy et al. 2020; Baranová and Katrenicová 2018). Therefore, understanding the students' motivation level in the learning process is crucial for educational success (Tang and Austin 2009; Lin et al. 2010; Sha et al. 2012). Similarly, usability, immersion, interaction, learning styles, the type of emerging technology used, enjoyment and ease of use, among others, are variables that might have an impact on learners' motivation (Bacca et al. 2018; Lau and Lee 2021).

Practical lectures based on the use of ICTs have favored teaching in spatial geometry (Olmedo-Torre et al. 2017). In the world of ICTs, virtual reality (VR) and augmented reality (AR) are the innovative technologies that have most rapidly been introduced into many fields, such as cultural heritage and architecture (Koeva et al. 2017) and the daily medical practice (Balsam et al. 2019), among others. Likewise, these technologies have provided promising results in the educational field (Kesim and Ozarslan 2012; Cabero-Almenara et al. 2019), gaining influence on teaching (Zhigeng et al. 2006; Dunleavy 2014; Serin 2020), with most of their applications being in simulation activities for the learning of science, technology, engineering and mathematics (STEM) (Ibañéz and Delgado-Kloos 2018). VR is an immersive, software-hardware-based 3D environment that users can explore by moving their own bodies (Pan et al. 2006). VR reflects the interface between 3D graphics and real-time software applications (Stone 1995), providing a sense of reality through the dynamic environment developed by computers (Serin 2020). On the other hand, AR is the visualization of the real physical environment through a technological device, normally a tablet or a mobile phone (Bazarov et al. 2017; Zhou et al. 2008), which adds, in real time, virtual elements to complement the physical reality (Azuma 1997). Therefore, while in VR the experience is based on a computergenerated virtual environment, in AR the environment is real (Lee 2012). In this context, some authors stated that the use of VR (Mayrose 2012; Prasolova-Førland et al. 2017; Lau and Lee 2021) and AR (Ke and Hsu 2015; Kugelmann et al. 2018) applications in the education sector drives students into an active learning, improving their motivation toward the academic contents, especially in science subjects. Prince (2004) strongly encouraged engineering faculty to implement active learning in their lectures. In the area of graphic engineering, both VR and AR can help by allowing students to enhance their learning, making it interactive. Visualizing the exercises in VR and AR improves the students' capacity of spatial vision, since certain movements (e.g., turning the objects up to $360^{\circ}$ throughout the students' own rotation movement) are allowed (Baranová and Katrenicová 2018). The utilization of these technologies inside the classroom allows the learners to perceive individually geometric elements in an interactive manner (Tumkor 2018), supporting a better understanding of the subjects with graphic expression contents (Viegas et al. 2018), and increasing their enthusiasm (Huerta-Cardoso et al. 2019). The effectiveness of these methodologies and technologies applied in the learning process is based on the motivation of the learners (TallentRunnels et al. 2006), with involvement in learning being a key factor (Zimmerman 1989). 
Some research on the motivation of students caused by the application of different technological scenarios in AR has been made in Vocational Education and Training and in Educational Science at the University level (Bacca et al. 2018; Cabero-Almenara et al. 2019). The use of AR tools (Hanafi et al. 2017) and VR (Starr et al. 2019) in the learning process might help to improve academic motivation for both male and female students. Nevertheless, the effective use of such a novel tool may be mediated by several factors, such as gender (Hanafi et al. 2017). To the best of our knowledge, gender has been identified as an important pedagogical factor in the last decades (Kim and Baylor 2006). Kim and Lim (2013) found that student gender was a significant factor in the learners' evaluations, although few studies have tackled motivation. Although some authors claimed that female learners might have greater motivation (Caspi et al. 2008; Yukselturk and Bulut 2009), the motivational level of university students as a function of gender has not been thoroughly explored, and few publications address the motivational improvements among students when implementing innovative 3D graphical techniques.

The aim of this paper was to assess how 3D-visualization exercises through innovative technologies, such as VR and AR, can increase the level of motivation in different typologies of university students in comparison with conventional lectures, as well as to identify the students' preferences and perceptions toward the use of these 3D resources.

\subsection{Student motivation assessment}

There have been several attempts to assess the motivation level of students, when implementing these ICTs, since motivation is one of the major factors related to performance success in the subject in which they use them (Ayala-Alvarez et al. 2017; Cabero-Almenara and Roig-Vila 2019). Authors such as Ayala-Alvarez et al. (2017) and Melian-Melian and Martín-Gutierrez (2018) have studied the usability of 3D learning objects applied in graphical expression. Keller (1987) developed the attention, relevance, confidence and satisfaction (ARCS) model of motivational design, based on 4 factors: attention (perceptual arousal, inquiry arousal and variability), relevance (goal orientation and motive matching), confidence (learning requirements, success opportunities and personal responsibility) and satisfaction (intrinsic reinforcement) from the point of view of the learners. Many authors have implemented this model to know the students' motivation toward the use of different items, such as podcasting and web-based courses (Bolliger et al. 2010; Cook et al. 2009; Kew et al. 2018). Keller also developed a specific instrument called Instructional Materials Motivation Survey (IMMS) (Keller 2010). The IMMS has been implemented in different studies and validated as a reasonable and effective instrument in the assessment of how this instructional material can affect the motivation of learners (Rodgers and Withrow-Thorton 2005; Johnson 2012; Huang and Hew 2016), and it has also been tailored by custom questionnaires to better accommodate the motivational features to specific studies (Bolliger et al. 2010; Kew et al. 2018).

\section{Materials and methods}

\subsection{Materials}

\subsubsection{The sample}

This study was performed during the academic year 2019-2020 with a sample of university students of two different profiles: engineering and non-engineering students. The engineering subsample was constituted by first-year students and included 39 undergraduates in Industrial Electronic Engineering, 32 undergraduates in Agricultural Engineering and 22 undergraduates in Forestry Engineering. On the other hand, the non-engineering subsample included 21 masters-degree students in Teacher Training of Secondary Education and bachelor's degree, Professional Training and Language Education in 'Drawing, Image and Graphics Arts' specialty. Additionally, for the engineering group, this study included data from the 20 tutored undergraduate students who needed an additional explanation. The great variability of the sample makes the results potentially generalizable at the university level.

Based on the experience of the faculty over the last years, there is great variability in the level of drawing skills presented by first-year students for engineering degrees. Some of them had not taken the so-called Technical Drawing subject in the course before entering the University. Other students lacked the spatial vision needed for undertaking these disciplines. According to administrative data from the University, the subject 'Technical Drawing' had a pass rate of 41 out of 100 enrolled students over the last 4 years.

\subsubsection{Teaching resources: 3D exercises}

The present study is focused on the development of 3D elements for the improvement of visualization exercises. Apart from the perspective sketches made on the blackboard and used in the conventional lectures, eleven exercises of technical drawing were developed in a three-dimensional (3D) coordinate system. These digitized 3D/CAD versions of the exercises were created using CAD software and subsequently processed using Sketchfab software, in order to enable their visualization through WebXR Device API technology, commonly used with VR and AR devices. The content built with the WebXR standard technologies delivers an immersive experience in VR that is compatible with 
the most modern web browsers in PC and smartphones. This new way of visualizing the exercises enables students to observe the geometric objects from different angles and different points of view, facilitating their understanding and conveying an accurate sense of scale in VR and AR (Gutiérrez de Ravé et al. 2016). 3D-modeling exercise is the link between the three-dimensional volume, which is displayed, and the two-dimensional graphical representation (AyalaAlvarez et al. 2017). The aim of 3D-modeling exercise is to facilitate the understanding of dihedral projection system representation exercises (double orthogonal cylindrical projection on the horizontal and vertical projection planes) and axonometric system representation exercises (Fig. 1). These $3 \mathrm{D}$ exercises, provided by the lecturers, were uploaded to the educational university platform Moodle 2019/2020, in order to make them available to the students at any time inside and outside the classroom (Ayala-Alvarez et al. 2017). 3D exercises could be visualized three-dimensionally through any device, turning them around with the fingers (smartphones or tablets) or computer mouse (laptop or computers), and even through the head-mounted VR glasses in a much more immersive and enjoyable way (Fig. 2) (Atsikpasi and Fokides 2021). The head-mounted glasses used in this study were the Oculus Quest model.

\subsection{Methodology}

\subsubsection{Study design and procedure (instrument-IMMS)}

Lectures were taught by instructors from the same University department, using innovative 3D tools and some standard teaching materials which are commonly used in their classes.

The lecturers taught the contents of the subject explaining the exercises on the blackboard, having different supporting material resources, such as PowerPoint presentations and

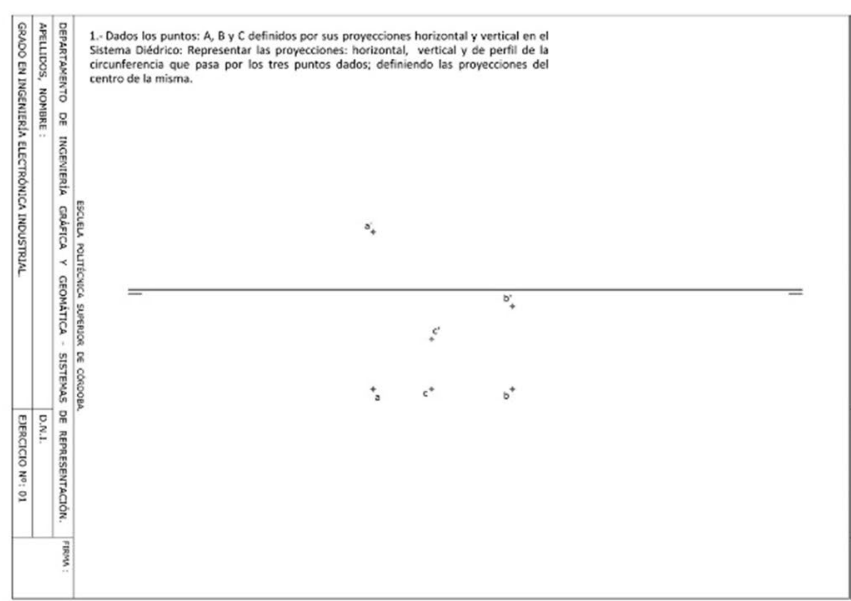

(a)

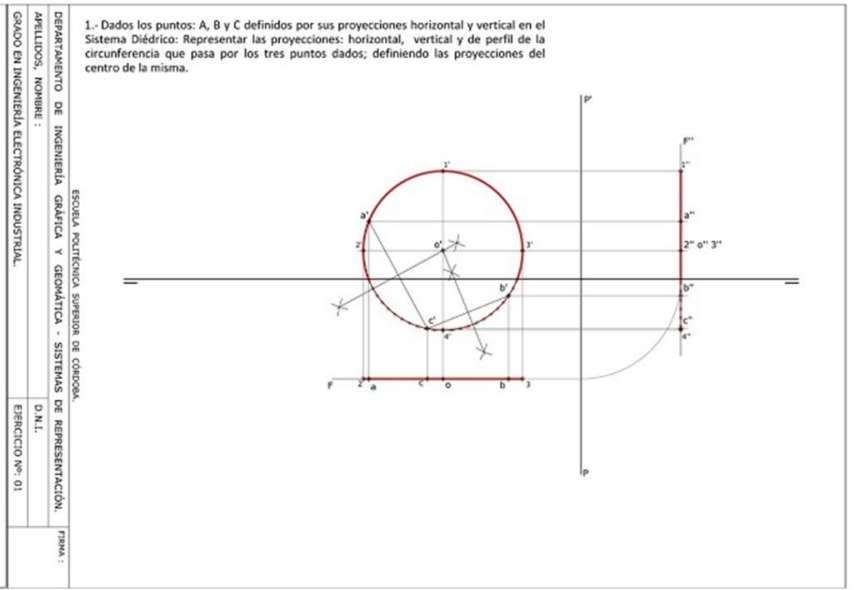

(b)

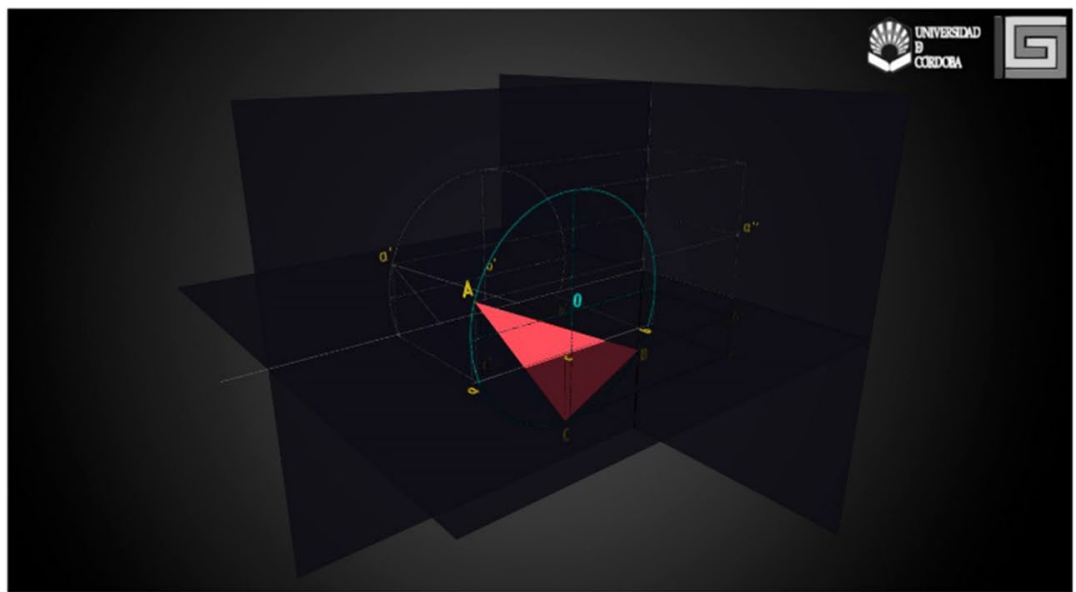

(c)

Fig. 1 Example of a resolved exercise in the dihedral projection system. a Exercise graphical statement, b solution of the 2D exercise on paper and $\mathbf{c}$ screenshot of the 3D visualization obtained with the computer (Sketchfab 2020) 


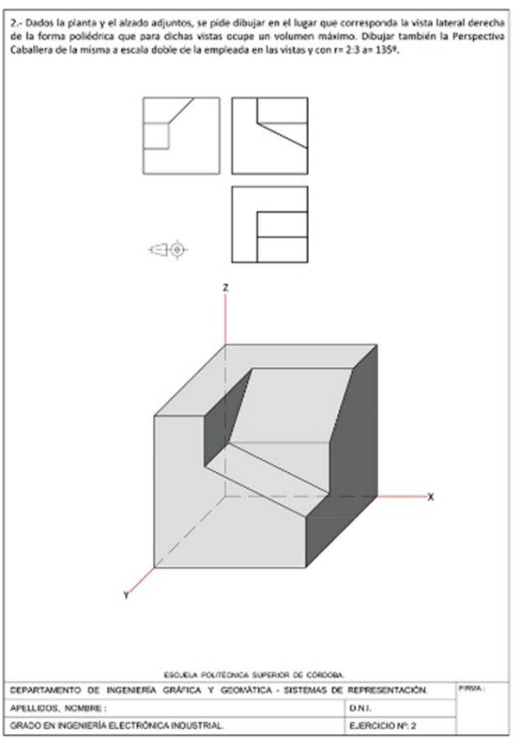

(a)

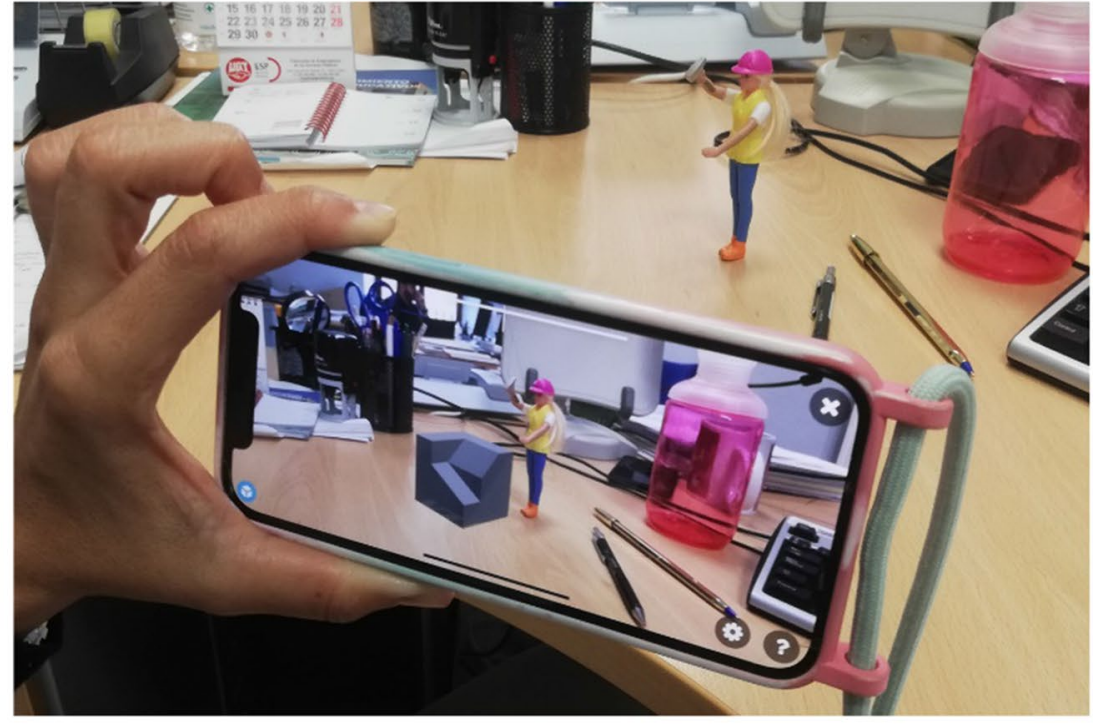

(b)

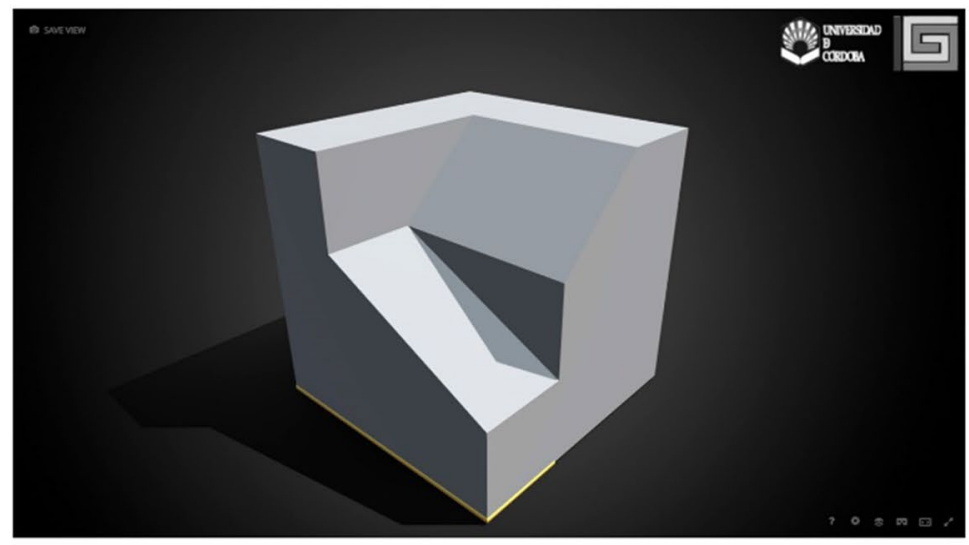

(c)

Fig. 2 Example of an exercise of axonometric projection. a Exercise graphical solution in paper (2D format), b visualization of the exercise with augmented reality and $\mathbf{c}$ screenshot of the 3D visualization with virtual reality obtained with the computer (Sketchfab 2020)

slides. After having performed the normal and conventional procedure, the lecturers provided the students with this innovative $3 \mathrm{D}$ teaching material, which could be seen with their smartphones, tablets, computers, etc. The students were free to observe the different 3D models as often as they wished, since they had the URL addresses of the different exercises uploaded to the University Moodle platform. The students could open them on any mobile device before performing them individually in paper (2D format). In addition, there was the possibility to visualize the exercises with the headmounted virtual glasses for students attending a tutoring session with the instructor (Fig. 3).

After using these teaching resources throughout the term in several exercises, the lecturers conducted an anonymous questionnaire to collect data from each student. There was information, on the first page of the questionnaire explaining that this experience was built within the framework of an innovation project conducted by the Graphic Engineering and Geomatics Department of the University.

A panel of experts composed of researchers and academics of the Graphical Engineering Department of the University created this outline survey for this research. The questionnaire had questions in two different approaches. The first part tackled the attitude of the students with respect to spatial vision, their skills using ICT, their previous knowledge on technical drawing for university students, and the gender of the respondents. The second part of the survey approached the usefulness and feasibility of the 3D tools and assessed how these innovative 3D resources affect learner motivation. In this second part, the authors investigated the relationships among attention, relevance, confidence, and satisfaction in graphical expression for undergraduates and 


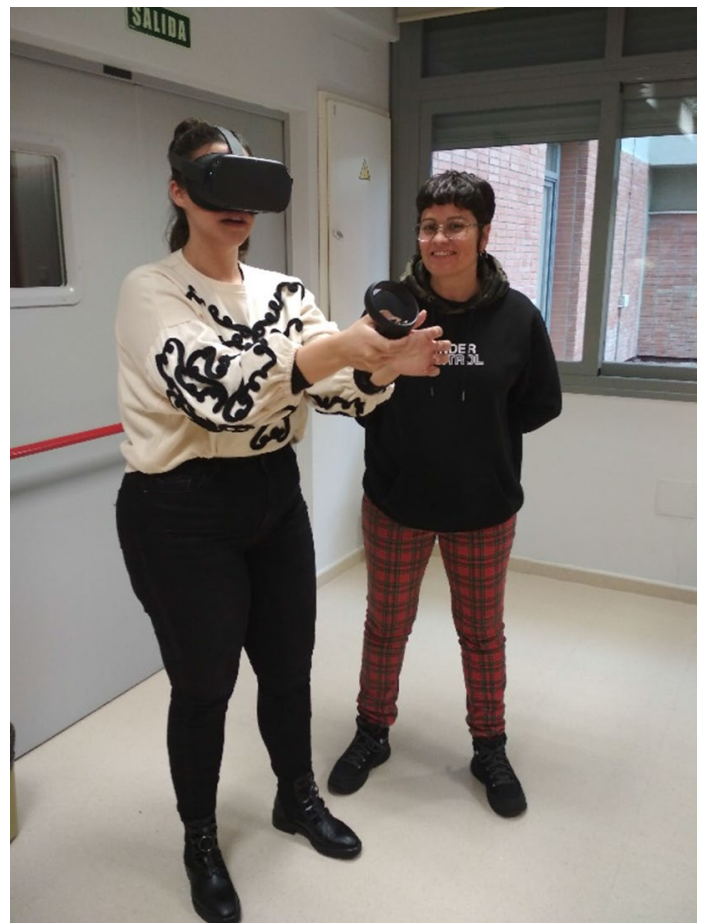

Fig. 3 Masters' students using virtual reality to visualize 3D representations with the head-mounted glasses

postgraduates, through the modified IMMS. This questionnaire was administered to the students in class once they had observed the provided 3D exercises through different devices, at the end of the course. The selected method for motivation assessment was based on the modified IMMS. The modified instrument contains 24 questions with 5-point Likert-scale items that measure the motivational reactions of the learners to the new self-directed instructional material. This instructional model studies the four strategies that need to be met for people to become motivated according to the ARCS model: attention, motivation, confidence, and satisfaction. The responses range from ( 0 - strongly disagree) to (5-strongly agree). Each query of the questionnaire corresponds to one of the four previously mentioned categories.

\subsubsection{Statistical data analysis}

The data were analyzed using Excel (Microsoft) software. The statistic selected for data analysis after data collection was Cronbach's alpha coefficient $(\alpha)$. This statistic offers the instrument's internal reliability or internal consistency of the answers to a quantified questionnaire (Leontitsis and Page 2007). The Cronbach's alpha coefficient or reliability index for the modified IMMS was 0.90, which means an 'excellent internal consistency' $(0.9 \leq \alpha)$. Reliability estimates for each category were classified as 'good' for the attention factor ( $\alpha=0.86)(0.8 \leq \alpha<0.9)$, 'questionable' for the relevance factor $(\alpha=0.65)(0.6 \leq \alpha<0.7)$ and 'acceptable' for the confidence $(\alpha=0.72)$ and satisfaction $(\alpha=0.70)$ aspects, respectively $(0.7 \leq \alpha<0.8)$. From the point of view of validation, the internal consistency shows its lowest value (0.86) for the attention category. Table 1 shows the values for IMMS in its different dimensions.

An independent $t$ test was conducted to determine differences in mean scores based on the gender of the students, i.e., between males and females, in the four categories. The usefulness of these new technologies was studied calculating the mean $(M)$ and standard deviation (SD) of the four Likert scaled questions $(0-5)$ that were related to spatial vision and the students' skill to execute the exercises. The suitable timing to use them was studied by asking the students to choose the best of three given possibilities: (a) 'after reading the exercise statement and before thinking about it'; (b) 'after thinking about the exercise and before its execution'; or (c) 'after thinking about the exercise and after its execution.'

\section{Results}

\subsection{Sample description}

One hundred and thirty-four students $(42.27 \%$ of the total enrolled students), corresponding to $79.28 \%$ of students committed to the subject and taking exams, completed the survey. Five surveys were deleted from the data set, since one-third of the data were missing. Most of the respondents were male $(71.64 \%), 84.33 \%$ were undergraduate students, and $15.68 \%$ were master-degree and postgraduate students. The breakdown of the participants was related to their engineering-focused degrees, their gender and their previous knowledge of technical drawing (Table 2).

The undergraduate students belonged to the Industrial Electrical and Engineering segment and were enrolled in the subject 'Representation Systems,' whereas the Agricultural and Forestry Engineering students were enrolled in the subject 'Engineering Drawing,' which is mainly composed of the same didactic contents as the previous one. Masters students were enrolled in the subject called teaching innovation
Table 1 Reliability index of the instructional materials motivation survey (IMMS) instrument

\begin{tabular}{llllll}
\hline & Attention & Relevance & Confidence & Satisfaction & Total \\
\hline Cronbach's alpha $(\alpha)$ & 0.86 & 0.65 & 0.72 & 0.70 & 0.90 \\
Consistency & Good & Questionable & Acceptable & Acceptable & Excellent
\end{tabular}


Table 2 Description of the sample

\begin{tabular}{llll}
\hline & Tutorial students & Undergraduate students & $\begin{array}{l}\text { Post- } \\
\text { graduate } \\
\text { students }\end{array}$ \\
\hline Total & 20 & 93 & 21 \\
Females & 5 & 25 & 8 \\
Males & 15 & 68 & 13 \\
Industrial electronic engineering & 5 & 39 & \\
Agricultural engineering & 10 & 32 & 8 \\
Forestry engineering & 5 & 22 & 5 \\
New enrolment students with previous & 5 & $28(\mathrm{a})+10(\mathrm{~b})+2(\mathrm{c})$ \\
$\quad$ knowledge on technical drawing & 7 & $5(\mathrm{a})+11(\mathrm{~b})+9$ (c) \\
New enrolment students with no knowl- & 7 & $6(\mathrm{a})+11(\mathrm{~b})+11(\mathrm{c})$ & 0 \\
$\quad$ edge on technical drawing & 8 & & \\
Repeater students & &
\end{tabular}

(a) Undergraduate students of Industrial Electronic Engineering; (b) Undergraduate students of Agricultural Engineering; (c) Undergraduate students of Forestry Engineering in 'Drawing, Image and Graphic Arts,' in which this study was performed.

The survey respondents were asked to provide their insight into ICTs tools. The results showed that the masterdegree students indicated a medium level of knowledge $(M=2.52)$, whereas the undergraduate students showed a high level of knowledge in Industrial Electronic Engineering $(M=3.67)$, in Agricultural Engineering $(M=2.84)$ and in Forestry Engineering $(M=2.82)$. Concerning the spatial vision, master-degree students and those in Agricultural Engineering thought that they had an average level $(M=3.00$ and 2.91, respectively), whereas the undergraduates studying Industrial Electronic Engineering and Forestry Engineering estimated greater results $(M=3.36$ and 3.40, respectively).

\subsection{Research questions related to the ARCS model}

The response scale for the ARCS model ranges from 0 to 5: (0-strongly disagree); (1-disagree); (2—slightly disagree); (3-slightly agree); (4-agree) and 5 (strongly agree). Therefore, the minimum and the maximum scores in the overall IMMS are 0 and 120, respectively, for each participant, which means a range of $0-670$ for the total sample. The total scores of the surveyed students ranged from 213 to 343 $(M=313)$. These findings reflect the view that, overall, most of the students were motivated to use these innovative $3 \mathrm{D}$ learning resources.

Table 3 depicts descriptive statistics for the four categories of the whole sample (graduate and undergraduate students). The highest and lowest mean scores were generated by one question of the relevance subscale $(M=4.26)$ and one of the confidence subscale $(M=2.85)$. The results support that the lecturers' ability to brief students on the usefulness of 3D techniques has a significant influence on their future engineering profession, and on their perception of learning improvement thanks to the emerging resources.

Only one item of the attention subscale ('The quality of the $3 D$ drawings helps to improve my attention') had a mean score above 4.0 (Fig. 4) in the whole sample. Attention and confidence subscales mean scores were higher for the postgraduate group than for the undergraduate group, whereas the other two subscales were lower for the postgraduate group. The statistical analyses determined that $81.30 \%$ of the participants strongly agreed or normally agreed with the statement that the quality of the 3D drawings helps to improve their attention. Around $76 \%$ of the students strongly agreed or agreed in that these 3D learning and teaching resources helped them to increase their motivation (76.1\%), as well as their curiosity (74.60\%), whereas $64.20 \%$ of the surveyed students agreed (strongly or normally) in that the diversity of content when utilizing 3D resources helped them
Table 3 Descriptive statistics for the four subscales (attention, relevance, confidence and satisfaction)

\begin{tabular}{llllllll}
\hline ARCS—subscales & \multicolumn{2}{l}{ Mean $(\mathrm{M})$} & & \multicolumn{3}{l}{ Standard deviation (SD) } \\
\cline { 2 - 3 } & Sample & Postgraduates & Undergraduates & & Sample & Postgraduates & Undergraduates \\
\hline Attention & 3.90 & 3.97 & 3.89 & 1.02 & 0.99 & 1.03 \\
Relevance & 4.01 & 3.85 & 4.04 & & 0.98 & 0.93 & 0.97 \\
Confidence & 3.63 & 3.71 & 3.62 & & 1.10 & 1.21 & 1.07 \\
Satisfaction & 3.92 & 3.88 & 3.93 & & 0.94 & 0.93 & 0.95 \\
\hline
\end{tabular}


Fig. 4 Mean scores and standard deviations of the 'attention' subscale

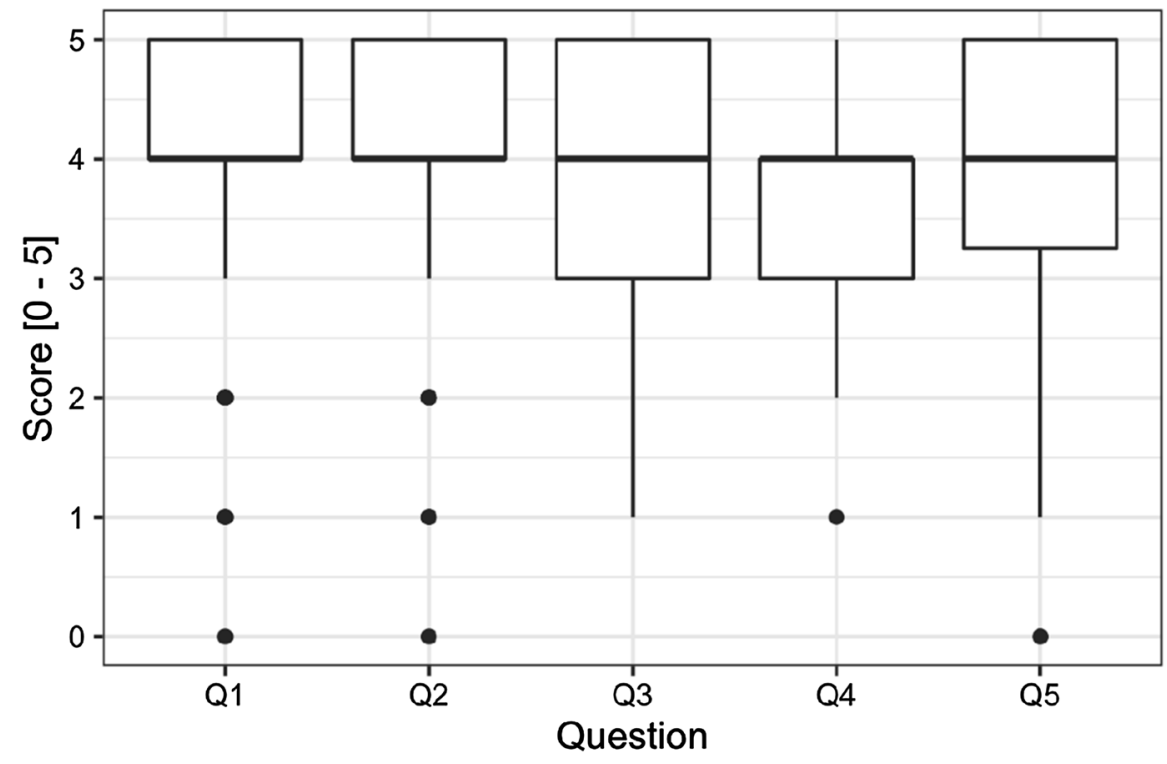

Q1: The 3D resource is very motivating

Q2: The quality of the 3D drawing helps to improve my attention

Q3: 3D representations stimulate my curiosity for the subject

Q4:The diversity of content when utilizing 3D resources helps to keep my attention Q5: Visualizing the exercises in 3D increases my curiosity for their realization to retain their attention. Figure 4 displays the statistical data for the five items of the attention factor.

Figure 5 indicates the means and the standard deviations of the relevance factor. Two items of this second factor-subscale ('The content uploaded to Moodle of this type of resources has a high value for engineering degrees' and 'augmented reality could improve my learning in these graphical subjects') had a mean score above 4.0. More than 90\% of the participants agree (strongly or slightly), highlighting the relevance of these 3D resources (VR and AR), while $94 \%$ of the participants agreed in that the content provided with these tools had a high value for their professional career; however, $90.30 \%$ agreed in that these 3D resources were not compulsory for them, since they already knew the contents.

The statistical data corresponding to the confidence factor are shown in Fig. 6. One item of this third factor-subscale had a mean score above 4.0. This item concerns the understanding of the improvements through the observation of the exercises in 3D. A total of $93.30 \%$ of the surveyed students agreed (strongly, normal or slightly) with this understanding of the improvements in the contents, due to the visualization of the exercises with the support of the 3D tool, realizing a better understanding (91.00\%), more clearly (94.00\%). However, nearly $87 \%$ of the participants stated that they will be able to do the task without the help of these innovative 3D resources. Figure 6 shows the lower mean score of the entire questionnaire (2.85), corresponding to the query regarding how abstract the contents of the dihedric and axonometric systems are to students, which can make them difficult to study. In this context, it is important to note that not all these higher-degree and masters' students had previous knowledge on these disciplines.

The satisfaction factor, which yielded the highest mean score (4.09), corresponded to the question regarding the study of the exercises through these 3D instruments (Fig. 7). The participants agreed (normally or strongly) with the fact that these digital resources increased their satisfaction level when observing the exercises for the very first time (70.90\%), when resolving exercises $(70.10 \%)$ and when studying the contents $(79.10 \%)$.

\subsubsection{Data results according to gender}

An independent Student's $t$ test was conducted to assess the differences in mean scores between males and females in the four subcategories. The results showed no significant differences between males and females in any subscale (Attention- $t(132)=0.03, p=0.01 ;$ Relevance- $t(132)=0.04$, $p=0.01 ;$ Confidence $-t(132)=0.07, p=0.01 ;$ Satisfac tion- $t(132)=0.14, p=0.01)$.

As presented in Table 4, the male participants had higher means in all the subscales (Attention- $M=3.80 ; \mathrm{SD}=1.01$; Relevance $-M=3.88 ; \mathrm{SD}=1.00 ;$ Confidence $-M=3.82$; $\mathrm{SD}=1.01 ;$ Satisfaction $-M=3.83 ; \mathrm{SD}=0.98)$ with respect to the female participants (Attention $-M=3.78 ; \mathrm{SD}=1.07$; 


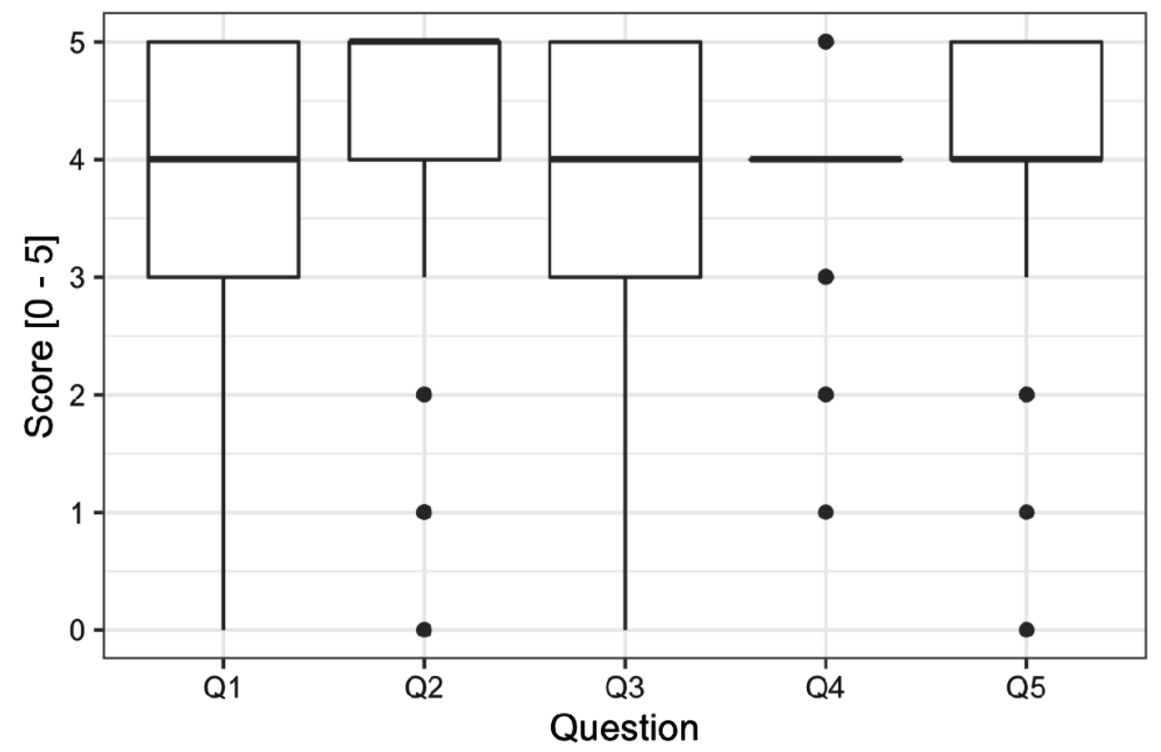

Q1:The theoretical contents have been relevant to me after the visualization of the exercises in $3 D$

Q2: The content uploaded to Moodle of this type of resources has a high value for engineering degrees

Q3: What this type of resource in 3D provides is not necessary for me, since I know most of the contents

Q4: The contents provided by this type of resources in 3D will be useful in my professional career

Q5: Augmented Reality could improve my learning in these graphical subjects

Fig. 5 Mean scores and standard deviations of the 'relevance' subscale

Relevance $-M=3.85 ; \mathrm{SD}=1.06 ;$ Confidence $-M=3.76$; $\mathrm{SD}=1.09 ;$ Satisfaction $-M=3.72 ; \mathrm{SD}=1.14)$. The greatest difference was obtained in the 'Satisfaction' subscale, with the males having 11 more points than the females. However, the most balanced category was 'Attention,' with 2 points of difference.

\subsection{Usefulness and suitability of the 3D resources}

Table 5 depicts descriptive statistics for the four questions asked to the participants and related to the usefulness of using the 3D digital resources. The visualization of 3D modeling exercises speeds up the knowledge acquisition that each student must achieve, relating spatial geometry to plane geometry. The highest mean score was obtained in the enhancement of the understanding of the exercises (4.15) and the improvement in spatial vision (4.01).

The students visualized the 3D exercises utilizing different devices (e.g., smartphones, tablets, computers, laptops and 3D glasses for virtual reality). Laptops and computers offer a similar 3D visualization, which can be turned around with the mouse to see it in $360^{\circ}$, whereas using the mobile or the tablets, the visualization can be turned around using the fingers, or with the head-mounted glasses using one's own body movements. The participants were asked about the suitability of any of these devices for reaching our purpose through a $0-5$ Likert scale ( 0 represents that the device was unsuitable, whereas 5 shows the highest value, meaning that it is very suitable). Table 6 indicates the statistical results of the aptness of these devices.

All the four evaluated devices had high mean scores (above 3.00), meaning that each 3D resource itself was welcome by the student. However, the head-mounted glasses $(M=4.09 ; \mathrm{SD}=1.61)$ and the laptop or computer $(M=3.95$; $\mathrm{SD}=1.13$ ) were the preferred devices for the students. There was no preference for neither of the two remaining 'visualization tools' (smartphone and tablet) since their means were quite similar. A total of $63.83 \%$ of the students scored with 5 (the highest mark of the Likert scale) when asked about the suitability of the head-mounted glasses that were used for the virtual-reality exercises. The percentages of students who allocated 5 points to the suitability of 3D exercises visualization were: $20.93 \%$ for smartphones, $22.13 \%$ for tablets and $36.22 \%$ for computers and laptops. Figure 8 shows the students' perception of each available device to observe the $3 \mathrm{D}$ exercises.

\subsection{The time for using these innovative tools}

A total of 128 out of 134 participants answered the survey concerning the best time to use the 3D visualization. 'After thinking about the exercise and before its execution' was the 


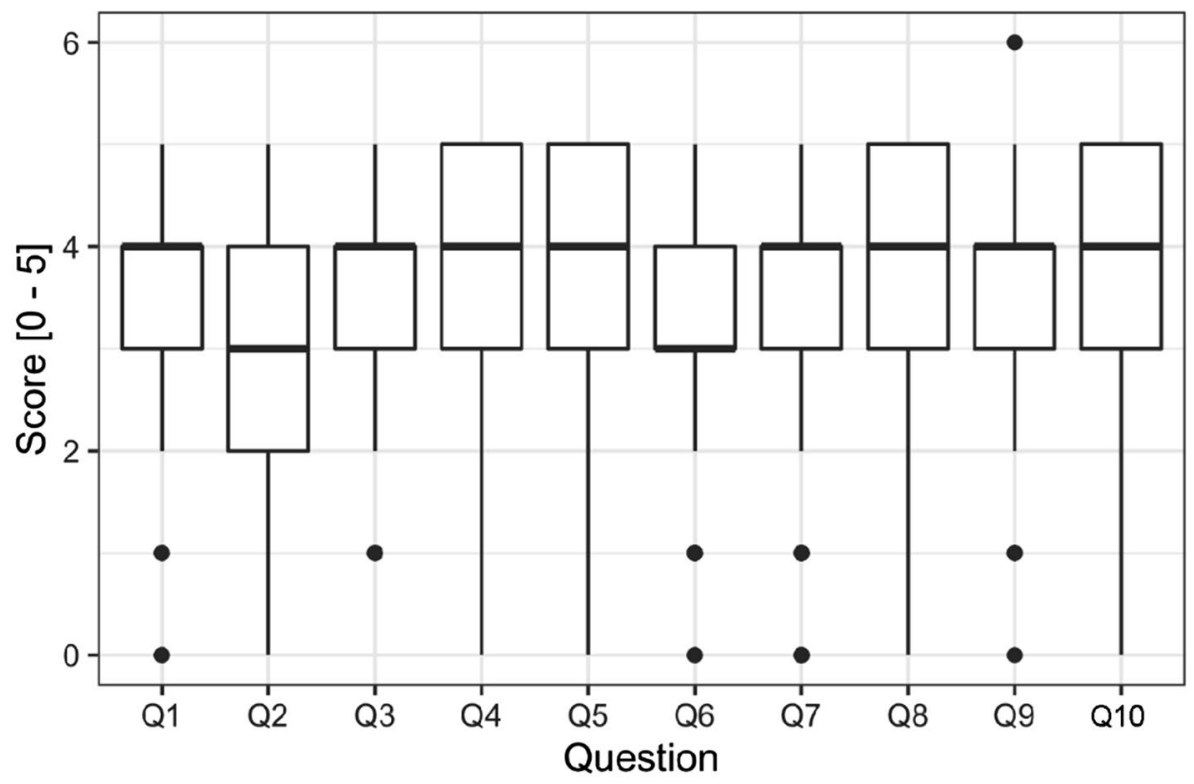

Q1: I consider myself capable of performing the exercises without this 3D resource

Q2: The theoretical contents (diedric and axonometric systems) are so abstract that both present difficulties to be studied through the 3D modelling tools

Q3: The subject contents have been studied and better understood after observing the 3D exercises

Q4: The previous contents of technical drawing that I knew so far have become clearer with the use of these $3 \mathrm{D}$ courses

Q5: The understanding of the exercises improves with the observation of the resource in $3 D$

Q6: Performing the paper exercises would have been very difficult without this kind of 3D resource

Q7: I would pass a test on an exercise that I just saw in 3D

Q8: My level of understanding of $3 \mathrm{D}$ exercises is high

Q9: These drawings / resources in 3D have improved my learning (with respect to the contents) and the level of understanding of the exercises, facilitating their interpretation

Q10: Observing the 3D drawings through the head-mounted glasses for Virtual Reality improves the comprehension of the exercises

Fig. 6 Mean scores and standard deviations of the 'confidence' subscale

most supported option for both undergraduates and postgraduates (Fig. 9).

Figure 10 shows a graphical comparison among the three possible timings for utilizing the innovative techniques. Using the 3D-visualization technique after thinking about the exercise and before its execution was the most supported option for the undergraduates $(60.26 \%)$ and the tutorial students $(55.00 \%)$, whereas, for the masters students, the best option for using this tool was after thinking about the exercise and after its execution (43.75\%).

\section{Discussion}

As was stated by Prince (2004), research findings acknowledge the positive influence of the elements for active learning on engineering students. It is clear that $3 \mathrm{D}$ visualization provides an added value to any object to be represented and interpreted (Koeva et al. 2017). However, in the educational fields of technical and engineering drawing, our results are in agreement with those found in the literature (Ayala-Alvarez et al. 2017), since, in a 5-point Likert scale, the respondents showed a high mean score $(M=3.80 ; \mathrm{SD}=1.14)$ regarding the innovative resource's usefulness. According to Villa et al. (2018), students tend to have difficulties in understanding the 3D shape of objects starting from their two-dimensional representations, concerning their spatial vision. However, in this study, the mean score of the participants about their own assessment of spatial vision was as follows: 3.00 $(\mathrm{SD}=1.08)$ for masters' degree students, $3.22(\mathrm{SD}=1.09)$ for undergraduate students and $2.70(\mathrm{SD}=0.98)$ for tutorial students.

In line with Carbonell-Carrera and Saorin (2018), no gender differences were detected in measuring the usefulness of the $3 \mathrm{D}$ resources in improving spatial vision between males $(M=4.01 ; \mathrm{SD}=0.97)$ and females $(M=4.00 ; \mathrm{SD}=0.97)$. 
Fig. 7 Mean scores and standard deviations of the 'satisfaction' subscale

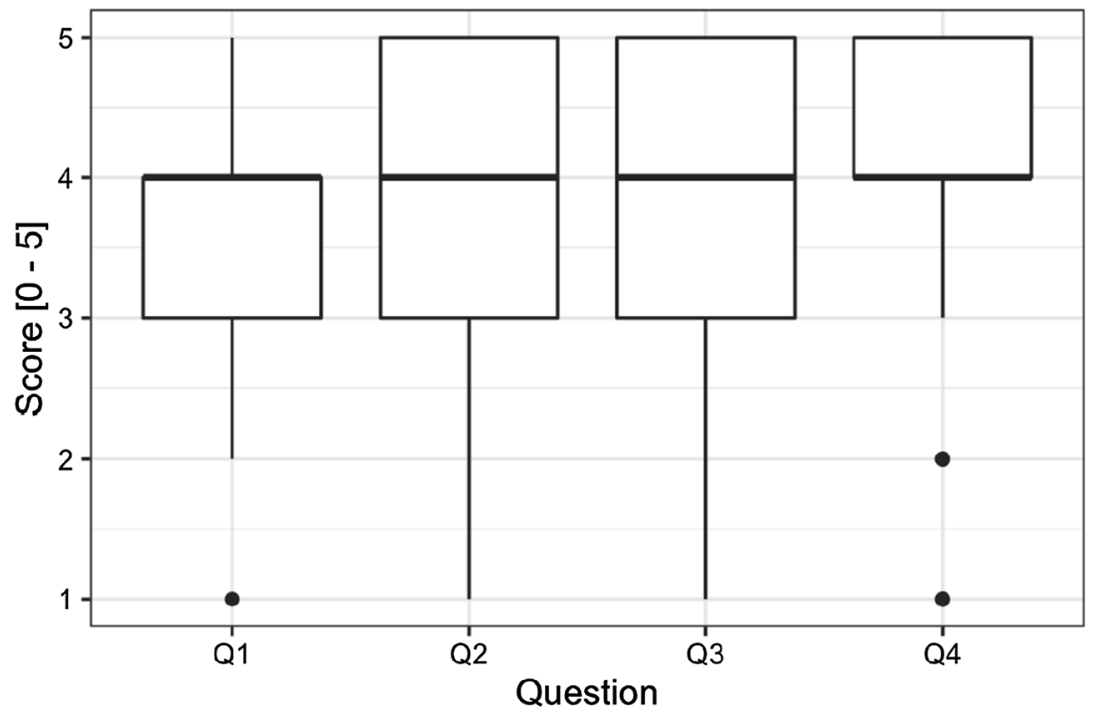

Q1: The first impression when I observed the exercises performed in 3D was very good with respect to the ease in its realization

Q2: My initial impression regarding the ease of understanding the 3D material even if we had not had it

Q3: Using these exercises in $3 \mathrm{D}$ increases my degree of satisfaction regarding the resolution of exercises

Q4: I enjoyed studying the realization of the exercises through these resources in $3 D$
Table 4 Descriptive statistics for the four subscales (attention, relevance, confidence and satisfaction) according to gender

\begin{tabular}{llllll}
\hline ARCS_subscales & \multicolumn{2}{l}{ Mean (M) } & & \multicolumn{2}{l}{$\begin{array}{l}\text { Standard deviation } \\
(S D)\end{array}$} \\
\cline { 2 - 3 } \cline { 6 - 6 } \cline { 5 - 6 } & Male & Female & & Male & Female \\
\hline Attention & 3.80 & 3.78 & & 1.01 & 1.07 \\
Relevance & 3.88 & 3.85 & & 1.00 & 1.06 \\
Confidence & 3.82 & 3.76 & & 1.01 & 1.09 \\
Satisfaction & 3.83 & 3.72 & & 0.98 & 1.14 \\
\hline
\end{tabular}

Concerning gender, and conversely to what was stated by Caspi et al. (2008) and Yukselturk and Bulut (2009), our findings showed slightly higher values of motivation for males $(M=3.83$; $\mathrm{SD}=1.00)$ using these innovative virtual tools than for females $(M=3.78 ; \mathrm{SD}=1.09)$. In agreement with our results, Di Serio et al. (2013) analyzed the improvement of secondary education students' motivation in Spain, and pointed out that their attention, interest, confidence and satisfaction increased with the use of augmented reality. Likewise, research developed on university engineering students applying AR technologies for studying descriptive geometry showed a positive impact on their spatial ability (Gutiérrez de Ravé et al. 2016), as well as higher academic performance and motivation level (Martín-Gutiérrez and Meneses-Fernández 2014).

The literature review of Garzón et al. (2019) concluded that AR tools increase learning gains and motivation. Indeed, our findings reflect that AR tools would increase students' motivation $(M=4.16 ; \mathrm{SD}=0.92)$. Encheva (2017) explored the improvement in the higher education sector in Bulgaria, by utilizing technologies for virtual and augmented reality, and highlighted their potentialities concerning learning environments. Wojciechowki and Cellary (2013) also observed a positive learners' attitude when using AR environments. Bazarov et al. (2017) showed the effectiveness of applying AR technology for engineering students in contributing to the improvement of knowledge in relation to standard didactic materials. Likewise, our results coincide
Table 5 Descriptive statistics regarding the usefulness of the $3 \mathrm{D}$ resources

\begin{tabular}{lll}
\hline Questions related to the usefulness of the 3D resources & M & SD \\
\hline The usefulness of the 3D resource in improving your spatial vision & 4.01 & 0.97 \\
The usefulness of the 3D resource in enhancing the understanding of the exercises & 4.15 & 1.10 \\
The usefulness of the 3D resource in identifying your errors and mistakes in the space & 3.52 & 1.20 \\
The usefulness of the 3D resource in performing the exercises in your paper sheet & 3.53 & 1.28 \\
\hline
\end{tabular}


Table 6 Descriptive statistics regarding the suitability of the devices for visualizing the $3 \mathrm{D}$ exercises

\begin{tabular}{lll}
\hline 3D-visualization device & $\mathrm{M}$ & $\mathrm{SD}$ \\
\hline Smartphone & 3.40 & 1.36 \\
Tablet & 3.39 & 1.58 \\
Laptop or computer & 3.95 & 1.13 \\
Head-mounted glasses for virtual & 4.09 & 1.61 \\
$\quad$ reality & & \\
\hline
\end{tabular}

with what was found in studies conducted in other research fields, such as Art, Medicine and Educational Technology (Cabero-Almenara et al. 2019), which documented that AR constitutes a useful means to facilitate learning and knowledge acquisition.

Our results support what was highlighted by authors such as Gunawan et al. (2017) and Serin (2020) concerning the greater level of satisfaction shown by students using these innovative technologies and enjoying while learning, with respect to the traditional learning methods. The mean score in a 5-point Likert scale was $4.90(\mathrm{SD}=0.94)$. Our findings also endorse what was asserted by Olmedo-Torre et al. (2017), regarding the increase in the students' satisfaction when introducing Information and Communications Technology (ICT) in the learning-teaching process. The mean score for the satisfaction concept, analyzed as a whole in this study, was $3.92(\mathrm{SD}=0.94)$ in a 5-point Likert scale, with $71.26 \%$ of all surveyed students agreeing with the positive influence, regarding the satisfaction of students, thanks to the implementation of these ICT tools for graphic expression in engineering university degrees, whereas Olmedo-Torre et al. (2017) reported a smaller percentage $(66 \%)$.

Conversely to other authors who did not find any clear preference of the students for any of the visualization tools used (Ayala-Alvarez et al. 2017), our results show a remarkable inclination for the virtual reality goggles or headmounted glasses, as they obtained a higher score than the rest of the devices. A total of $95.7 \%$ of the students preferred the head-mounted glasses as the suitable device to visualize these exercises, as the percentage from all three 'agree' categories (slightly agree + agree + strongly agree) was the

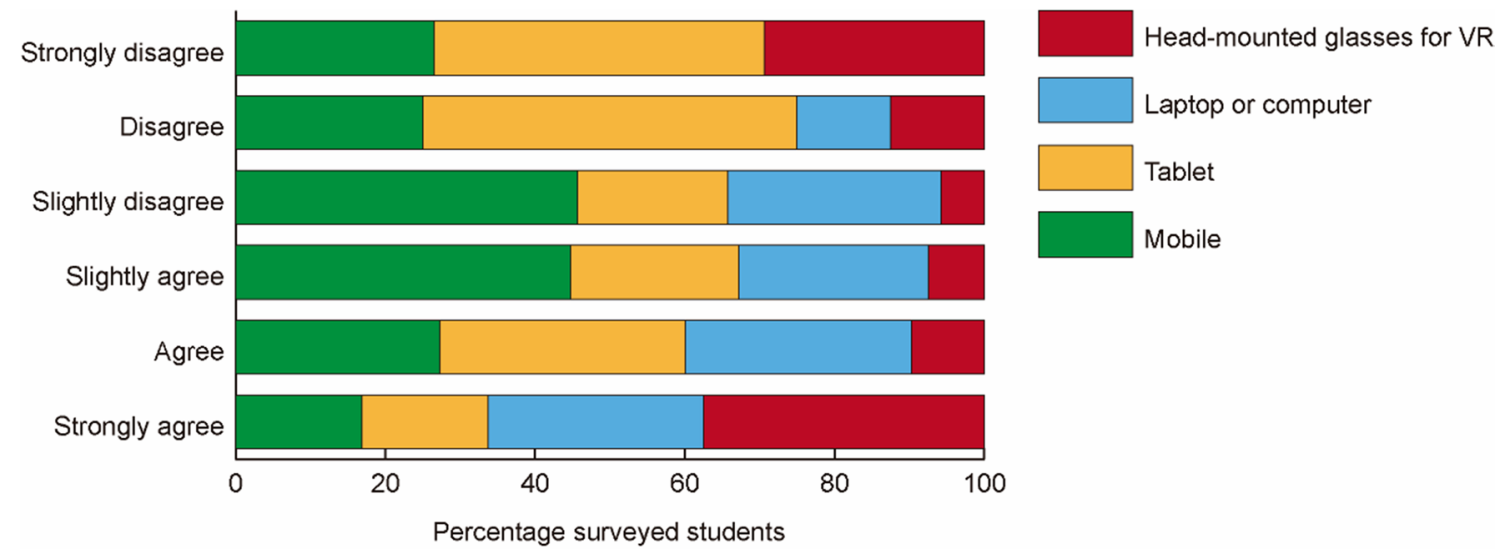

Fig. 8 Students' perception of each 3D-visualization device

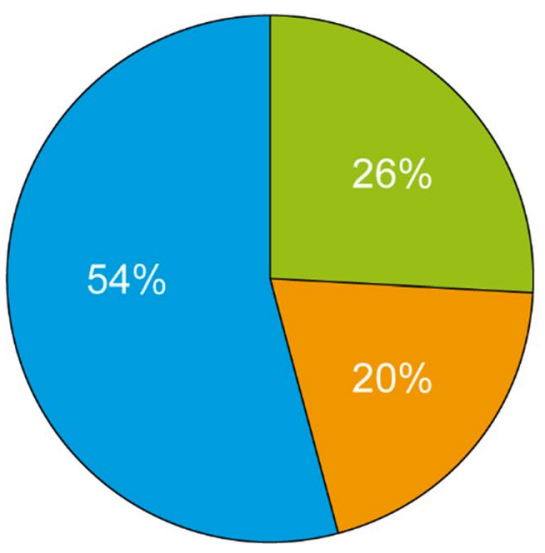

After reading the statement and before thinking about the exercise

After thinking about the exercise and after its execution

After thinking about the exercise and before its execution

Fig. 9 Students' preferences on the optimal timing for visualizing the 3D exercises 


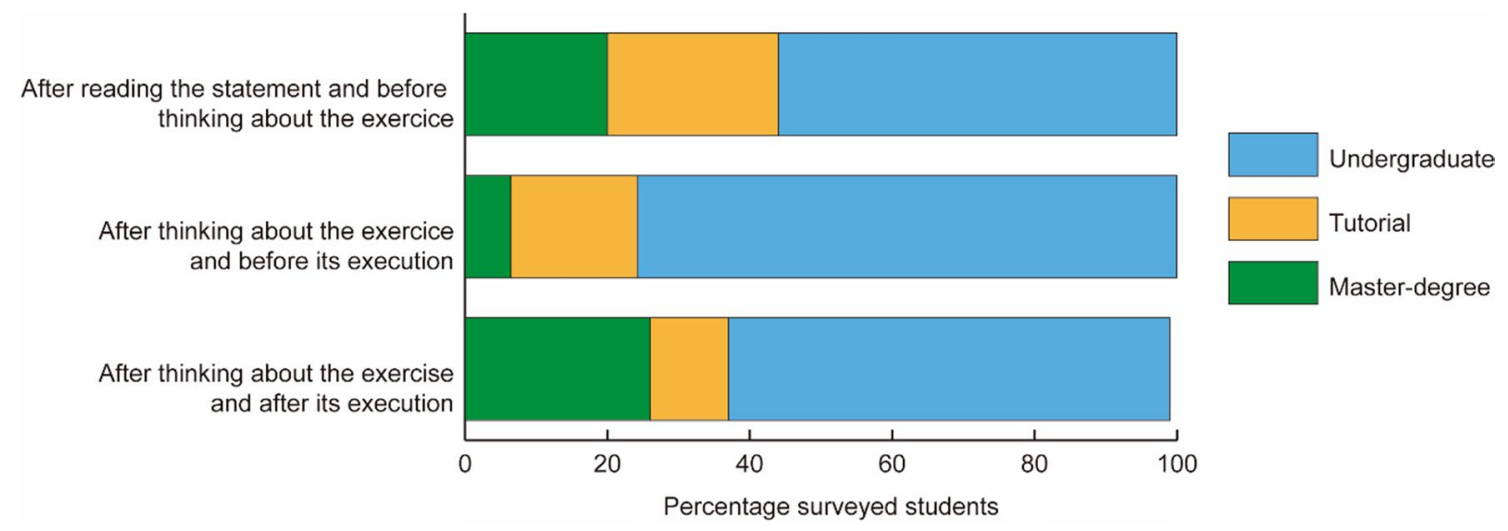

Fig. 10 Breakdown of students' preferences on the optimal timing to visualize the $3 \mathrm{D}$ exercises per type of student

highest. Particularly, 65.9\% strongly agreed with the idea that the VR glasses were the best device, as they provide users with a more realistic environment (Park et al. 2020). However, according to what was found by Ayala-Alvarez et al. (2017), there was no clear preference for neither of the three other visualization tools (smartphones, tablets or computers) (Fig. 11).

\section{Conclusions}

The use of virtual and augmented reality aims to complement the conventional methodology applied in the course, in both the theoretical and practical lectures, to facilitate learning. These technologies should be more integrated into new educational models, where students might be increasingly oriented toward e-based learning.

The questionnaire raised within this research at this University has served to validate the ARCS model, as a sound instrument to assess the motivation of students in the graphical expression segment of the bachelor's degrees in engineering and master degree.

Students reacted positively to the inclusion of 3D resources in their learning process. The VR and AR technologies that are shown in this study enhance the motivation of these engineering and masters' degree students, thereby facilitating their e-learning process. The 'relevance' factor certainly reached a higher mean score for both male and female students within the four categories of the ARCS motivational model. The greatest difference in gender was observed for the 'Satisfaction' subscale, although no significant differences were found between males and females in any category of the ARCS model.

Concerning the most suitable device for visualizing 3D exercises, the head-mounted glasses, used for VR visualization, were the preferred option of students, since they provide a complete immersion in the virtual world. The optimal timing to utilize these innovative learning resources in basic courses, for undergraduate and tutored students, was 'after thinking about the exercise to be solved and before its execution.' Conversely, the best time to benefit from these

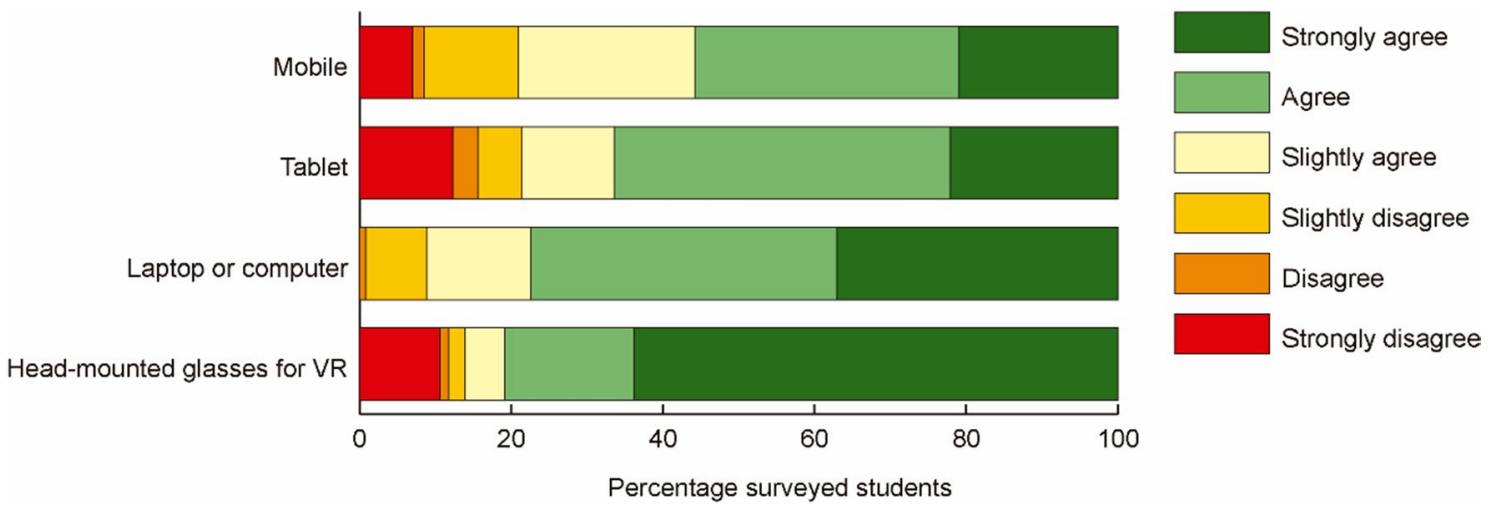

Fig. 11 Students' assessment of each 3D-visualization device. Note the head-mounted glasses were not used for the Electronical Engineering degree 
emerging technologies for the masters' degree and postgraduate students was 'after thinking about the exercise and after its execution.'

This work contributes to justifying the enrichment of the learning process for graphic expression subjects at the university level with 3D-visualization resources, due to the increase in academic motivation, as well as to the positive attitude of students toward innovative technologies (VR and AR). Although this research documents VR and AR as useful tools for self-reported learning, students' cognitive gains were not tested, which could be the focus of further research.

Acknowledgements The authors wish to thank the University of Cordoba in Spain for providing the opportunity to carry out the teaching innovation project entitled 'Improvements in the teaching-learning process of graphic Representation Systems through virtual and augmented reality tools (2019-1-5009).' This research work provides the framework for the procedures that follow from this kind of e-Learning, and the authors would like to thank all of the students that have actively participated in this project, which looks to the future of developing different and better methods. The authors respect the support of the students who have participated in this research exercise. Thank you.

Author contributions PT-T and PC-C contributed to the conceptualization; PT-T, P.C-C and R-EH-F. were involved in the methodology; PC-C and R-EH-F contributed to the validation; PT-T, PC-C and AM-G were involved in the investigation; PT-T and AM-G. contributed to the resources; PT-T and F-JM-C contributed to the data curation; PT-T contributed to the writing-original draft preparation; P-T-T, P.C-C, R-EH-F and F-JM-C were involved in the writing - review and editing; PT-T, P-C-C and F-JM-C contributed to the supervision. All authors have read and agreed to the published version of the manuscript.

Funding Open Access funding provided thanks to the CRUE-CSIC agreement with Springer Nature. This research is framed within a teaching innovation project entitled 'Improvements in the teachinglearning process of graphic Representation Systems through the use of virtual and augmented reality tools.' The project falls in the field of Engineering and Architecture studies, which belongs to the Innovation Plan and Best Teaching Practices 2019/2020 of the University of Cordoba (Spain) (UCO 2020).

Availability of data and materials The data and material can be provided upon request from Paula Triviño-Tarradas (ig2trtap@uco.es).

\section{Declarations}

Conflict of interest The authors declare no conflict of interest.

Open Access This article is licensed under a Creative Commons Attribution 4.0 International License, which permits use, sharing, adaptation, distribution and reproduction in any medium or format, as long as you give appropriate credit to the original author(s) and the source, provide a link to the Creative Commons licence, and indicate if changes were made. The images or other third party material in this article are included in the article's Creative Commons licence, unless indicated otherwise in a credit line to the material. If material is not included in the article's Creative Commons licence and your intended use is not permitted by statutory regulation or exceeds the permitted use, you will need to obtain permission directly from the copyright holder. To view a copy of this licence, visit http://creativecommons.org/licenses/by/4.0/.

\section{References}

Adanez GP, Dias Velasco A (2002) Predicting academic success of engineering students in technical drawing from visualization test scores. J Geom Graph 6(1):99-109

Atsikpasi P, Fokides E (2021) A scoping review of the educational uses of 6DoF HMDs. Virtual Real. https://doi.org/10.1007/ s10055-021-00556-9

Ayala-Alvarez F, Blazquez-Parra EB, Montes-Tubio F (2017) Improving graphic expression training with 3D models. J vis 20(4):889 904. https://doi.org/10.1007/s12650-017-0424-8

Azuma RT (1997) A survey of augmented reality. Presence Teleoperators Virtual Environ 6(4):355-385. https://doi.org/10.1162/ pres.1997.6.4.355

Bacca J, Baldiris S, Fabregat R, Kinshuk. (2018) Insights into the factors influencing student motivation in augmented reality learning experiences in vocational education and training. Front Psychol. https://doi.org/10.3389/fpsyg.2018.01486

Balsam P, Borodzicz S, Malesa K, Puchta D, Tymińska A, Ozierański K, Peller M, Grabowski M, Filipiak KJ, Opolski G (2019) OCULUS study: virtual reality-based education in daily clinical practices. Clin Cardiol 26(3):260-264

Baranová L, Katrenicová I (2018) Role of descriptive geometry course in development of students' spatial visualization skills. Ann Math Inform 49:21-32. https://doi.org/10.33039/ami.2018. 04.001

Barton BA, Adams KS, Browne BL, Arrastia-Chisholm MC (2021) The effects of social media usage on attention, motivation, and academic performance. Act Learn High Educ 22(1):11-22. https://doi.org/10.1177/1469787418782817

Bazarov SE, Kholodilin IY, Nesterov AS, Sokhina AV (2017) Applying augmented reality in practical classes for engineering students. IOP Conf Ser Earth Environ Sci 87:32004. https://doi. org/10.1088/1755-1315/87/3/032004

Bennett S, Maton K, Kervin L (2008) The 'digital natives' debate: a critical review of the evidence. Br J Educ Technol 39(5):775786. https://doi.org/10.1111/j.1467-8535.2007.00793.x

Bolliger DU, Supanakorn S, Boggs C (2010) Impact of podcasting on student motivation in the online learning environment. Comput Educ 55(2):714-722. https://doi.org/10.1016/j.compe du.2010.03.004

Cabero-Almenara J, Roig-Vila R (2019) The motivation of technological scenarios in augmented reality (AR): results of different experiments. Appl Sci 9:2907. https://doi.org/10.3390/app91 42907

Cabero-Almenara J, Barroso-Osuna J, Llorente-Cejudo C, FernándezMartínez MM (2019) Educational uses of augmented reality (AR): experiences in educational science. Sustainability 11(18):4990

Carbonell-Carrera C, Saorin JL (2018) Virtual learning environments to enhance spatial orientation. EURASIA J Math Sci Technol Educ 14(3):709-719. https://doi.org/10.12973/ejmste/79171

Caspi A, Chajut E, Saporta K (2008) Participation in class and in online discussions: gender differences. Comput Educ 50:718-724. https://doi.org/10.1016/j.compedu.2006.08.003

Chang S, Hwang G (2018) Impacts of an augmented reality-based flipped learning guiding approach on students' scientific project performance and perceptions. Comput Educ 125:226-239

Chen H, Feng K, Mo C, Cheng S, Guo Z, Huang Y (2011) Application of augmented reality in engineering graphics education. In: 2011 IEEE international symposium on IT in medicine and education, vol 2, pp 362-65. https://doi.org/10.1109/ITiME.2011.6132125

Chester I (2007) Teaching for CAD Expertise. Int J Technol Des Educ 17(1):23-35. https://doi.org/10.1007/s10798-006-9015-Z

Cook DA, Beckman TJ, Thomas KG, Hompson WG (2009) Measuring motivational characteristics of courses: applying Keller's 
instructional materials motivation survey to a web-based course. Acad Med 84(11):1505-1509

Duffy G, Sorby S, Bowe B (2020) An investigation of the role of spatial ability in representing and solving word problems among engineering students. J Eng Educ. https://doi.org/10.1002/jee.20349

Dunleavy M (2014) Design principles for augmented reality learning. TechTrends 58(1):28-34. https://doi.org/10.1007/ s11528-013-0717-2

Encheva M (2017) Virtual and augmented reality in the higher education sector in Bulgaria. In: ICERI proceedings. 10th international conference of education, research, and innovation, pp 3703-3705

Feng J, Spence I, Pratt J (2007) Playing an action video game reduces gender differences in spatial cognition. Psychol Sci 18(10):850 855. https://doi.org/10.1111/j.1467-9280.2007.01990.x

Garzón J, Pavón J, Baldiris S (2019) Systematic review and metaanalysis of augmented reality in educational settings. Virtual Real 23:447-459. https://doi.org/10.1007/s10055-019-00379-9

Gerson HBP, Sorby SA, Wysocki A, Baartmans BJ (2001) The development and assessment of multimedia software for improving 3-D spatial visualization skills. Comput Appl Eng Educ 9(2):105-113. https://doi.org/10.1002/cae.1012

Gunawan M, Suranti N, Nisrina N, Ekasari R, Herayanti L (2017) Investigating students creativity based on gender by applying virtual laboratory to physics instruction. In: International conference on teacher training and education 2017 (ICTTE 2017), Surakarta, Indonesia, October 7, 2017

Gutiérrez de Ravé EG, Jiménez-Hornero FJ, Ariza-Villaverde AB, Taguas-Ruíz J (2016) DiedricAR: a mobile augmented reality system designed for the ubiquitous descriptive geometry learning. Multimed Tools Appl 75:9641-9663. https://doi.org/10.1007/ s11042-016-3384-4

Hanafi HF, Said CS, Wahab MHA, Samsudin KA (2017) Improving students' motivation in learning ICT course with the use of a mobile augmented reality learning environment. In: International research and innovation summit (IRIS2017) IOP conference series-materials science and engineering, vol 226. https://doi.org/ 10.1088/1757-899X/226/1/012114

Hsi S, Linn MC, Bell JE (1997) The role of spatial reasoning in engineering and the design of spatial instruction. J Eng Educ 86(2):151-158. https://doi.org/10.1002/j.2168-9830.1997.tb002 78. $\mathrm{x}$

Huang B, Hew KFT (2016) Measuring learners' motivation level in massive open online courses. Int J Inf Educ Technol 6(10):759-764

Huerta-Cardoso OI, Unver E, Aslan R, Kus A, Chotrov D (2019) Application of VR and AR tools for technical drawing education. In: CAD'19-the 16th annual international CAD conference, pp $363-66$

Hwang A, Arbaugh JB (2009) Seeking feedback in blended learning: competitive versus cooperative student attitudes and their links to learning outcome. J Comput Assist Learn 25:280-293

Ibañéz M, Delgado-Kloos C (2018) Augmented reality for STEM learning: a systematic review. Comput Educ 123:109-123

Johnson M (2012) A pilot study examining the motivational effect of instructional materials on EFL learning motivation. J Lang Culture Hokkaido 10:39-47

Kahle JN (1983) The disadvantages majority: sciences education for women. AETS Outstanding paper

Ke F, Hsu YC (2015) Mobile augmented-reality artifact creation as a component of mobile computer-supported collaborative learning. Internet High Educ 26:33-41. https://doi.org/10.1016/j.iheduc. 2015.04.003

Keller JM (1987) Development and use of DFFF the ARCS model of motivational design. J Instr Dev 10(3):2-10
Keller JM (2010) Motivational design for learning and performance. Springer, New York. https://doi.org/10.1007/978-1-4419-1250-3

Kesim M, Ozarslan Y (2012) Augmented reality in education: current technologies and the potential for education. Procedia Soc Behav Sci 47:297-302. https://doi.org/10.1016/j.sbspro.2012.06.654

Kew SN, Petsangsri S, Ratanaolarn T, Tasir Z (2018) Examining the motivation level of students in E-learning in higher education institution in Thailand: a case study. Educ Inf Technol 23(6):2947-2967. https://doi.org/10.1007/s10639-018-9753-Z

Kim Y, Baylor AL (2006) A social-cognitive framework for pedagogical agents as learning companions. Educ Technol Res Dev 54:569-596. https://doi.org/10.1007/s11423-006-0637-3

Kim Y, Lim JH (2013) Gendered socialization with an embodied agent: creating a social and affable mathematics learning environment for middle-grade females. J Educ Psychol 105(4):1164

Koeva M, Luleva M, Maldjanski P (2017) Integrating spherical panoramas and maps for visualization of cultural heritage objects using virtual reality technology. Sensors 17:829. https://doi.org/ 10.3390/s17040829

Kugelmann D, Sratmann L, Nühlen N, Bork F, Hoffmann S, Samarbarksh G, Pferschy A, von der Heide AM, Eimannsberger A, Fallavollita P, Navab N, Waschke J (2018) An augmented reality magic mirror as additive teaching device for gross anatomy. Ann Anat Anatomischer Anzeiger 215:71-77. https://doi.org/10. 1016/j.aanat.2017.09.011

Lau KW, Lee PY (2021) Using virtual reality for professional training practices: exploring the factors of applying stereoscopic 3D technologies in knowledge transfer. Virtual Real. https://doi.org/ 10.1007/s10055-021-00504-7

Lee K (2012) Augmented reality in education and training. TechTrends 56(2):13-21. https://doi.org/10.1007/s11528-012-0559-3

Leontitsis A, Page J (2007) A simulation approach on Cronbach's alpha statistical significance. Math Comput Simul 73:336-340

Lin CF, Lu MS, Chung CC, Yang CM (2010) A comparison of problem-based learning and conventional teaching in nursing ethics education. Nurs Ethics 17(3):373-382. https://doi.org/10.1177/ 0969733009355380

Lord TR (1985) Enhancing the visuo-spatial aptitude of students. J Res Sci Teach 22(5):395-405. https://doi.org/10.1002/tea.3660220503

Martín-Gutiérrez J, Meneses-Fernández MD (2014) Applying augmented reality in engineering education to improve academic performance and student motivation. Int J Eng Educ 30(3):1-11

Mayrose J (2012) Active learning through the use of virtual environments. Am J Eng Educ (AJEE) 3(1):13-18

Melian-Melian JA, Martín-Gutierrez J (2018) Design and usability of learning objects applied in graphic expression. Comput Appl Eng Educ 26(5):1134-1149. https://doi.org/10.1002/cae.21946

Millar R (2004) The role of practical work in the teaching and learning of science. Department of Educational Studies. University of York. Accessed 01 July 2021. https://sites.nationalacademies. org/cs/groups/dbassesite/documents/webpage/dbasse_073330.pdf

Morrison GR (1994) The media effects question-unresolvable or asking the right question. ETR\&D-Educ Technol Res Dev 42(2):41-44

Olmedo-Torre N, Farrerons Vidal O, Lapaz Castillo J, Bermúdez Rodríguez F (2017) The Influence of ICT on learning in graphic engineering. Procedia Soc Behav Sci 237:737-744. https://doi.org/10. 1016/j.sbspro.2017.02.115

Pan Z, Cheok AD, Yang H, Zhu J, Shi J (2006) Virtual reality and mixed for virtual learning environments. Comput Graph 30:20-28

Park KB, Kim M, Choi SH, Lee JY (2020) Deep learning-based smart task assistance in wearable augmented reality. Robot Comput Integr Manuf 63:101887

Parras-Burgos D, Fernández-Pacheco DG, Barbosa TP, Soler-Méndez M, Molina-Martínez JM (2020) An augmented reality tool for 
teaching application in the agronomy domain. Appl Sci-Basel 10(10):3632. https://doi.org/10.3390/app10103632

Pellas N, Fotaris P, Kazanidis I, Wells D (2019) Augmenting the learning experience in primary and secondary school education: a systematic review of recent trends in augmented reality gamebased learning. Virtual Real 23:329-346. https://doi.org/10.1007/ s10055-018-0347-2

Petersen GB, Klingenberg S, Mayer RE, Makransky G (2020) The virtual field trip: investigating how to optimize immersive virtual learning in climate change education. Virtual Learn Clim Change Educ. https://doi.org/10.31234/osf.io/m7vp9

Prasolova-Førland E, Molka-Danielsen J, Fominykh M, Lamb K (2017) Active learning modules for multi-professional emergency management training in virtual reality. In: 2017 IEEE 6th international conference on teaching, assessment, and learning for engineering (TALE), pp 461-68. https://doi.org/10.1109/TALE.2017.8252380

Prince MJ (2004) Does active learning work? A review of the research. J Eng Educ 93(3):223-231. https://doi.org/10.1002/j.2168-9830. 2004.tb00809.x

Prince MJ, Felder M (2006) Inductive teaching and learning methods: definitions, comparisons, and research bases. J Eng Educ 95(2): $123-138$

Rodgers DL, Withrow-Thorton BJ (2005) The effect of instructional media on learner motivation. Int J Instr Media 32(4):333-340

Serin H (2020) Virtual reality in education from the perspective of teachers. Amazon Investiga. https://doi.org/10.34069/AI/2020. 26.02.33

Serio ÁD, Ibáñez MB, Delgado Kloos C (2013) Impact of an augmented reality system on students' motivation for a visual art course. Comput Educ 68:586-596. https://doi.org/10.1016/j. compedu.2012.03.002

Sha L, Looi C-K, Chen W, Seow P, Wong LH (2012) Recognizing and measuring self-regulated learning in a mobile learning environment. Comput Hum Behav 28(2):718-728. https://doi.org/10. 1016/j.chb.2011.11.019

Sketchfab (2020) Accessed 02 July 2021. https://sketchfab.com/ DIBUJO_ETSIAM_1

Sorby SA (2009) Educational research in developing 3-D spatial skills for engineering students. Int J Sci Educ 31(3):459-480. https:// doi.org/10.1080/09500690802595839

Sorby SA, Baartmans BJ (2000) The development and assessment of a course for enhancing the 3-D spatial visualization skills of first year engineering students. J Eng Educ 89(3):301-307. https://doi. org/10.1002/j.2168-9830.2000.tb00529.x

Starr CR, Anderson BR, Green KA (2019) 'I'm a Computer Scientist!": virtual reality experience influences stereotype threat and STEM motivation among undergraduate women. J Sci Educ Technol 28:493-507. https://doi.org/10.1007/s10956-019-09781-z

Stone R (1995) The reality of virtual reality. World Class Des Manuf 2(4):11-17. https://doi.org/10.1108/09642369310091106

Tallent-Runnels MK, Thomas JA, Lan WY, Cooper S, Ahern TC, Shaw SM, Liu X (2006) Teaching courses online: a review of the research. Rev Educ Res 76(1):93-135. https://doi.org/10.3102/ 00346543076001093

Tang TL-P, Austin MJ (2009) Students' perceptions of teaching technologies, application of technologies, and academic performance. Comput Educ 53(4):1241-1255. https://doi.org/10.1016/j.compe du.2009.06.007

Taran C (2005) Motivation techniques in elearning. In: Fifth IEEE international conference on advanced learning technologies (ICALT'05), pp 617-19. https://doi.org/10.1109/ICALT.2005.206

Tumkor S (2018) Personalization of engineering education with the mixed reality mobile applications. Comput Appl Eng Educ 26(5):1734-1741. https://doi.org/10.1002/cae.21942

UCO, (2020). Final resolution of the teaching innovation plan 2019/2020 (Engineering and Architecture) University of Cordoba. Accessed 02 July 2021. https://sede.uco.es/bouco/bande jaAnuncios/BOUCO/2019/00660

Viegas C, Pavani A, Lima N, Marques A, Pozzo I, Dobboletta E, Atencia V, Barreto D, Calliari F, Fidalgo A, Lima D, Temporão G, Alves G (2018) Impact of a remote lab on teaching practices and student learning. Comput Educ 126:201-216. https://doi.org/10. 1016/j.compedu.2018.07.012

Villa V, Motyl B, Paderno D, Baronio G (2018) TDEG based framework and tools for innovation in teaching technical drawing: The example of LaMoo project. Comput Appl Eng Educ 26:1293-1305

Wojciechowki R, Cellary W (2013) Evaluation of learners' attitude toward learning in ARIES augmented reality environments. Comput Educ 68:570-585

Yukselturk E, Bulut S (2009) Gender differences in self-regulated online learning environment. Educ Technol Soc 12(3):12-22

Zhigeng P, Cheok AD, Yang H, Zhu J, Shi J (2006) Virtual reality and mixed reality for virtual learning environments. Comput Graph 30(1):20-28. https://doi.org/10.1016/j.cag.2005.10.004

Zhou F, Duh HB, Billinghurst M (2008) Trends in augmented reality tracking, interaction and display: a review of ten years of ISMAR. In: 2008 7th IEEE/ACM international symposium on mixed and augmented reality, pp 193-202. https://doi.org/10.1109/ISMAR. 2008.4637362

Zimmerman BJ (1989) A social cognitive view of self-regulated academic learning. J Educ Psychol US Am Psychol Assoc. https:// doi.org/10.1037/0022-0663.81.3.329

Zgoul MH, Kilani MI (2009) Development of a multimedia toolkit for engineering graphics education. Int J Emerg Technol Learn 4(3). https://doi.org/10.3991/ijet.v4i3.639

Publisher's Note Springer Nature remains neutral with regard to jurisdictional claims in published maps and institutional affiliations. 